\title{
Spiritual and Alternative Cancer Therapies: Strange Theories, Perhaps Wrong, but Useful
}

\author{
Harald Walach \\ School of Social Sciences and Samueli Institute, European Office, Northampton, UK
}

Ever since I entered the backwater of research in complementary and alternative medicine (CAM) 20 years ago, I carried out my own phenomenologically oriented field observation about what it is to be a successful therapist. Whenever I meet someone who has a great reputation as a healer or therapist, I query them about their theories, about what they think makes their work effective, what patients like about their therapy. And, of course, I study their demeanour, the way they communicate, how they behave and dress, the verbal, para-verbal and non-verbal signals they send, whether they radiate and convey confidence, humility, arrogance, security. I started with homeopathy. There are probably as many types of applying homeopathy as there are leading figures, if not therapists, in homeopathy. Present one difficult patient to ten different leaders of homeopathic schools and see what remedy they find. There would perhaps be as many different prescriptions as therapists. If you could reverse each therapeutic course and could study them all in sequence in one patient with different therapists, I am quite sure they would all heal the patient in question equally well. We cannot carry out such an experiment for obvious reasons. But it is a useful thought experiment. It teaches us that it is likely not the method (alone) but (mostly) the therapist that heals.

Therapists, doctors or practitioners use their method to convey their healing. And for the method to be effective the therapist has to believe in it. When I say believe, I mean more than just thinking 'oh well, it might work'. The therapist has to be sure that what he (or she) does is - in principle - helpful. He may well entertain a stance of openness and curiosity as to whether his approach might help this particular person. But in principle he needs to be sure about what he does. He needs to believe that what he does has a good, rational justification, is worthwhile doing, has some background, is validated, etc. In short, he needs a good theory, and he needs to be convinced that this theory and the practice derived thereof is justified and capturing some truth. So the therapeutic theory has one important function: it binds the therapist to his method, gives him a rationale for acting, supplies rules for decision making and exculpates him as a person if something goes wrong or does not work as it should. The task of the therapeutic model is not to describe the truth, which is a dainty lady and difficult to please, anyway. The task of the therapeutic model is to construct an individual cosmos of meaning, within which healing may (or may not) occur. J.D. Frank has called this role of the therapeutic theory a 'therapeutic or healing myth' [1], but 'myth' sounds a bit unscientific, so I am using the less offensive term 'model', as in fact it denotes the same.

Apparently, there are more and less effective therapeutic models. And very likely their effectiveness is not a general one but a very individual and particular one. While the homeopathic model might work for some people, it might not for others. While the spiritual healing model might work very well for people with a spiritual leaning, it might be completely offensive to scientifically minded folks. These might prefer the scientific medical model. I am very happy to admit the very simple fact that modern medical science has unravelled a multitude of facts that cannot be debated as myths and models alone. But when it comes to the application of that knowledge to a patient, the science is often not very helpful, and medicine boils down to what it really is: an applied art that uses (sometimes) scientific knowledge to find interventions that are (sometimes) scientifically validated [2].

Modern scientific medicine is no exemption to the observations made above: it uses a sometimes very strong, sometimes rather weak therapeutic model to justify the methods it applies. In the case of emergencies and acute diseases the model is very strong and effective. This can be gleaned from the fact that we have drastically reduced premature mortality that was due to hygiene problems and infectious diseases over the last century. (During the same period, we have raised the number

\begin{tabular}{ll}
\hline KARGER & @ 2007 S. Karger GmbH, Freiburg \\
Fax +4976145207 14 & Accessible online at: \\
$\begin{array}{l}\text { E-mail Information@Karger.de } \\
\text { www.karger.com }\end{array}$ & www.karger.com/brc
\end{tabular}


of people killed through scientifically validated methods in institutionalised manslaughters called 'war' exponentially, an observation that casts some doubt on the ubiquitous usefulness of scientific reasoning not bound to a moral code or by a trustworthy story about the meaning of life.) In the case of chronic and diffuse diseases the medical model is rather weak and ineffective. This can be derived from the fact that we are confronted with a rise in complex, chronic and often nonlocalisable diseases, such as chronic fatigue syndrome, fibromyalgia, depression and cancer that are the result of complex self-regulation failures [3] due to environmental, behavioural, genetic and sometimes even iatrogenic factors, and a highly complex interaction of all these together.

And because this is so, patients with complex and chronic diseases frequently turn to CAM practitioners for help. These practitioners seem to offer more 'holistic', hence more convincing therapeutic models. Are these models correct? Probably not. Does it matter? Probably not. This is true for the conventional model in chronic cases also. Take cancer as an example. The official story is the following: Cancer arises from a genetic dysregulation that allows cells to multiply that shouldn't. The freak cells spread in the body and cause colonies that also multiply. Stopping the freak cells from multiplying means killing the cancer. Hence we seek out ever more sophisticated cytostatic drugs or techniques, try to entice the immune system to tackle only the freak cells, leaving the rest alone, etc. All very well, but in many cases this model is only moderately effective or not effective at all, or effective at incredibly high costs. Is the theoretical model true? Up to a certain degree and coarse graining, yes. But questions remain: What caused the first freak cell to multiply and not stop in the first place? Why now, and not 5 years earlier or later? Why do only some people have that problem and others don't? Why has the immune system worked well until that fatal day when it overlooked the first freak cell and then took annual leave? We all know very well that only a small percentage of cancers can be really explained in full by genetical changes. Also, even strong cancerogenics such as tobacco smoke do not cause cancer in everybody. Where do the resilience and susceptibility factors come into the picture?

It is here that alternative stories start being told. Alternative practitioners might offer other therapeutic models: They want to boost the immune competence. Or they might offer to get to the 'root cause' that is a 'karmic trouble' in a 'past life', and so forth, on end. You try and invent a new story. It is likely already around. Are these stories true? Who cares.

Truth is the wrong question about such stories. The right question is about effectiveness. Does a story help to make a therapist more effective? Probably yes, if he or she believes in it. Does a therapeutic myth convey healing power? Probably yes, if the therapist lives it. Walk the talk! This is the therapeutic imperative.

A predicament arises here for the scientist-practitioner: In order for the therapeutic model to be effective it needs to be believed in and not questioned. In order for science to understand how healing operates, it needs to question beliefs and scrutinise. Thus, the homeopath needs to believe in his medicines, that something is 'in there' in order to be effective. The spiritual healer needs to believe in 'healing energies' and 'balancing of the ethereal body' or whatever his model suggests he should do. The reincarnation therapist needs to be convinced that cancer may be an expression of an unsolved karmic problem, and a particular psychotherapist will have to operate on the assumption that freeing up emotional energy and letting go of past pain will allow healing to take place. Researching the model as to its truth value and using it at the same time for healing is a contradiction in terms. This is, incidentally, the reason, why the best therapists are very often poor scientists, and the other way round, at least if they try to be both at the same time (Sigmund Freud and Fritz Perls are prime examples of both: Freud was reputedly not a very effective therapist, and Perls, an effective therapist, never wrote a single line that really makes scientific sense).

Do we have to give up, then, on a scientific understanding of those therapeutic models? No, I don't think so. How to proceed then? I suggest the following:

We need to separate effectiveness from theory and acknowledge that there are different therapeutic stories, models or myths for different purposes. Whether they are 'true' is an altogether different and complicated matter. However, we can study effectiveness. We just need to acknowledge that we have to use a multiplicity of methods to do so, and not derive a methodological dogma from one dominant therapeutic model $[4,5]$. This multiplicity of methods will have to include a mix and sequence of qualitative, naturalistic-observational, and experimental studies to gain a full picture. Also, we can study what makes therapeutic models and their protagonists effective.

I would like to submit the idea that true healing is likely to be based on similar mechanisms across disciplines [6], whether complementary, alternative, or conventional. The therapeutic story is just the glue that allows for creating a therapeutic system. The 'mechanism' is likely to be non-local: a correlational change in the physical system of the patient, analogous to the healing intention in the mind of the healer, doctor, surgeon. The therapeutic story and subsequent intervention is just a clever trick to transport this intention. For the healing to happen, the therapist has to believe in it, otherwise he or she is not effectively coupled to the patient. Whether the story is true, is another matter, and quite irrelevant for the healing itself. The potential mechanism for this, I submit, is at the moment quite speculative, but rational. We have called it generalised entanglement [6], in analogy to quantum entanglement proper, and have developed a theoretical model [7] that can be used to understand such weird things as homeopathy [8], spiritual healing [9], or transference phenomena in therapeutic space [10], which, following our model, is actually just the reverse of healing. We also have some experimental data to 
back the model, although this is another and again highly complicated matter. It need not concern effective therapists. They can go on believing in whatever system they find trustworthy. For the final and decisive element of healing turns out to be trust and faith. Those are the lubricants on which the mechanics of healing hinge. Everything else is decoration.

\section{References}

1 Frank JD: Persuasion and Healing: A Comparative Study of Psychotherapy. Baltimore, Johns Hopkins University Press, 1961.

2 Wieland W: Diagnose. Überlegungen zur Medizintheorie. Berlin, de Gruyter, 1975.

3 Hyland ME: A brief guide to extended network entanglement theory as a theory of healing and its empirical predictions. Forsch Komplementarmed Klass Naturheilkd 2003, 10:201-206.

4 Fønneb $\varnothing$ V, Grimsgaard S, Walach H, Ritenbaugh C, Norheim AJ, MacPherson H, Lewith G, Launso L, Koithan M, Falkenberg T et al.: Researching complementary and alternative treatments - the gatekeepers are not at home. BMC Med Res Methodol 2007;7. http://www.biomedcentral.com/ 1471-2288/7/7

5 Walach H, Falkenberg T, Fønnebø V, Lewith G, Jonas W: Circular instead of hierarchical - methodological principles for the evaluation of complex interventions. BMC Med Res Methodol 2006;6. http://www.pubmedcentral.nih.gov/ articlerender.fcgi? artid $=1540434$

6 Lucadou W, Römer H, Walach H: Synchronistic phenomena as entanglement correlations in generalized quantum theory. J Consciousness Stud 2007; 14:50-74.

7 Atmanspacher H, Römer H, Walach H: Weak quantum theory: complementarity and entanglement in physics and beyond. Foundations Physics 2002;32:379-406.

8 Walach H: Entanglement model of homeopathy as an example of generalized entanglement predicted by Weak Quantum Theory. Forsch Komplementarmed Klass Naturheilkd 2003;10:192-200.

9 Walach H: Generalized entanglement: a new theoretical model for understanding the Effects of Complementary and alternative medicine. J Altern Complement Med 2005;11:549-559.

10 Walach H: Generalisierte Verschränkung - Ein theoretisches Modell zum Verständnis von Übertragungsphänomenen. Z Psychotraumatol Psychol Med 2007;5: in print. 